University of Wollongong

Research Online

Faculty of Engineering and Information

Faculty of Engineering and Information

Sciences - Papers: Part A

Sciences

$1-1-2014$

\title{
Structure of the Li4Ti5012 anode during charge-discharge cycling
}

Wei Kong Pang

University of Wollongong,wkpang@uow.edu.au

Vanessa Peterson

Australian Nuclear Science and Technology Organisation, vep@ansto.gov.au

Neeraj Sharma

University of New South Wales

Je-Jang Shiu

Tatung University Taipei

She-Huang Wu

Tatung University Taipei

Follow this and additional works at: https://ro.uow.edu.au/eispapers

Part of the Engineering Commons, and the Science and Technology Studies Commons

Research Online is the open access institutional repository for the University of Wollongong. For further information contact the UOW Library: research-pubs@uow.edu.au 


\title{
Structure of the Li4Ti5012 anode during charge-discharge cycling
}

\author{
Abstract \\ The structural evolution of the "zero-strain" Li4Ti5012 anode within a functioning Li-ion battery during \\ charge-discharge cycling was studied using in situ neutron powder-diffraction, allowing correlation of the \\ anode structure to the measured charge-discharge profile. While the overall lattice response controls the \\ "zero-strain" property, the oxygen atom is the only variable in the atomic structure and responds to the \\ oxidation state of the titanium, resulting in distortion of the TiO6 octahedron and contributing to the \\ anode's stability upon lithiation/delithiation. Interestingly, the trend of the octahedral distortion on charge- \\ discharge does not reflect that of the lattice parameter, with the latter thought to be influenced by the \\ interplay of lithium location and quantity. Here we report the details of the Ti06 octahedral distortion in \\ terms of the $\mathrm{O}-\mathrm{Ti}-\mathrm{O}$ bond angle that ranges from $83.7(3)^{\circ}$ to $85.4(5)^{\circ}$. \\ Disciplines \\ Engineering | Science and Technology Studies \\ Publication Details \\ Pang, W., Peterson, V. K., Sharma, N., Shiu, J. \& Wu, S. (2014). Structure of the Li4Ti5012 anode during \\ charge-discharge cycling. Powder Diffraction, 29 (Suppl. S1), S59-S63.
}

This journal article is available at Research Online: https://ro.uow.edu.au/eispapers/3185 


\title{
Structure of the $\mathrm{Li}_{4} \mathrm{Ti}_{5} \mathrm{O}_{12}$ Anode during Charge-Discharge Cycling
}

\author{
Wei Kong Pang, ${ }^{1,2}$, Vanessa K. Peterson ${ }^{1, *}$, Neeraj Sharma ${ }^{3}$, Je-Jang Shiu ${ }^{4}$, She-huang \\ $\mathrm{Wu}^{4}$ \\ ${ }^{1}$ Australian Nuclear Science and Technology Organization, Locked Bag 2001, Kirrawee \\ DC, NSW 2232, Australia. \\ ${ }^{2}$ School of Mechanical, Materials, and Mechatronic Engineering, Institute for \\ Superconducting \& Electronic Materials, Faculty of Engineering, University of \\ Wollongong, NSW 2522, Australia. \\ ${ }^{3}$ School of Chemistry, University of New South Wales, Sydney NSW 2052, Australia. \\ ${ }^{4}$ Department of Materials Engineering, Tatung University, No.40, Sec. 3, Zhongshan N. \\ Rd., Taipei City 104, Taiwan (R.O.C). \\ ${ }^{*}$ Corresponding author.
}

The structural evolution of the "zero-strain" $\mathrm{Li}_{4} \mathrm{Ti}_{5} \mathrm{O}_{12}$ anode within a functioning Li-ion battery during charge-discharge cycling was studied using in-situ neutron powder diffraction, allowing correlation of the anode structure to the measured charge-discharge profile. Whilst the overall lattice response controls the "zero-strain" property, the oxygen atom is the only variable in the atomic structure and responds to the oxidation state of the titanium, resulting in distortion of the $\mathrm{TiO}_{6}$ octahedron and contributing to the anode's stability upon lithiation/delithiation. Interestingly, the trend of the octahedral distortion on charge-discharge does not reflect that of the lattice parameter, with the latter thought influenced by the interplay of Li location and quantity. Here we report the details of the $\mathrm{TiO}_{6}$ octahedral distortion in terms of the O-Ti-O bond angle that ranges from $83.7(3)$ to $85.4(5)^{\circ}$.

Key words: Li-ion battery; $\mathrm{Li}_{4} \mathrm{Ti}_{5} \mathrm{O}_{12}$; neutron diffraction; phase evolution.

\section{INTRODUCTION}

Li-ion batteries (LIBs) have higher energy density, portative design, and longer lifetime than comparable battery technologies (Tarascon et al., 2001). Spinel $\mathrm{Li}_{4} \mathrm{Ti}_{5} \mathrm{O}_{12}$, a so-called zero-strain insertion material, has been commercialized as an anode material because of its exceptional high rate performance, excellent cycling stability, and Li-insertion electrochemistry with formal potential of 1.55-1.56 V vs. $\mathrm{Li}^{+} / \mathrm{Li}$ (Ohzuku et al., 1995; Ronci et al., 2002; Cho et al., 2001). Generally speaking, $\mathrm{Li}-(\mathrm{de})$ intercalation in $\mathrm{Li}_{4+z} \mathrm{Ti}_{5} \mathrm{O}_{12}(z=0 \sim 3)$ proceeds through a two-phase reaction, as given in Eq. 1, resulting in very flat plateaus in the charge and discharge curves.

$$
\begin{aligned}
& (\mathrm{Li})^{8 a}\left(\mathrm{Li}_{1 / 3} \mathrm{Ti}_{5 / 3}\right)^{16 d} \mathrm{O}_{4}^{32 e}+x \mathrm{e}^{-}+x \mathrm{Li}^{+} \\
& \stackrel{\sim 1.55 \mathrm{~V}}{\longrightarrow}(1-x)(\mathrm{Li})^{8 a}\left(\mathrm{Li}_{1 / 3} \mathrm{Ti}_{5 / 3}\right)^{16 d} \mathrm{O}_{4}^{32 e}+x\left(\mathrm{Li}_{2}\right)^{16 c}\left(\mathrm{Li}_{1 / 3} \mathrm{Ti}_{5 / 3}\right)^{16 d} \mathrm{O}_{4}{ }^{32 e}
\end{aligned}
$$

$(\mathrm{Li})^{8 a}\left(\mathrm{Li}_{1 / 3} \mathrm{Ti}_{5 / 3}\right)^{16 d} \mathrm{O}_{4}{ }^{32 e}$ and $\left(\mathrm{Li}_{2}\right)^{16 c}\left(\mathrm{Li}_{1 / 3} \mathrm{Ti}_{5 / 3}\right)^{16 d} \mathrm{O}_{4}{ }^{32 e}$, where the site multiplicity and Wyckoff letter is shown in superscript, crystallize in the $F d \overline{3} m$ space group. $1 / 6^{\text {th }}$ of $16 d$ sites are occupied by the "electrochemically inert" Li, with the remainder occupied by Ti (see Figure 1).

a) To whom correspondence should be addressed. Electronic mail: vanessa.peterson@ansto.gov.au 
The "electrochemically active" $\mathrm{Li}$ occupies tetrahedral $8 a$ sites of the $\mathrm{Li}_{4} \mathrm{Ti}_{5} \mathrm{O}_{12}$ lattice and is repositioned together with newly inserted $\mathrm{Li}$ at octahedral $16 c$ sites to form stable $\mathrm{Li}_{7} \mathrm{Ti}_{5} \mathrm{O}_{12}$ upon Li-intercalation. The Li-(de)intercalation of $\mathrm{Li}_{4} \mathrm{Ti}_{5} \mathrm{O}_{12}$ is also reported to occur via the following solid-solution reaction (Eq. 2):

$$
\begin{aligned}
& (\mathrm{Li})^{8 a}\left(\mathrm{Li}_{1 / 3} \mathrm{Ti}_{5 / 3}\right)^{16 d} \mathrm{O}_{4}^{32 e}+x \mathrm{e}^{-}+x \mathrm{Li}^{+} \\
& \stackrel{\sim 1.55 \mathrm{~V}}{\longrightarrow}\left(\mathrm{Li}_{1-y}\right)^{8 a}\left(\mathrm{Li}_{x+y}\right)^{16 c}\left(\mathrm{Li}_{1 / 3} \mathrm{Ti}_{5 / 3}\right)^{16 d} \mathrm{O}_{4}{ }^{32 e}
\end{aligned}
$$

where $z, y \leq 1$.

The phase transition between $\mathrm{Li}_{4} \mathrm{Ti}_{5} \mathrm{O}_{12}$ and $\mathrm{Li}_{4+z} \mathrm{Ti}_{5} \mathrm{O}_{12}\left(\mathrm{Li}_{7} \mathrm{Ti}_{5} \mathrm{O}_{12}\right.$ in the two-phase mechanism), as outlined in Eq. 1 and 2, involves a $<0.1 \%$ change in the lattice volume. The Li accommodated by the anode results in changes to the Ti oxidation state, affecting the structure of the $\mathrm{TiO}_{6}$ octahedral framework (Figure 1).

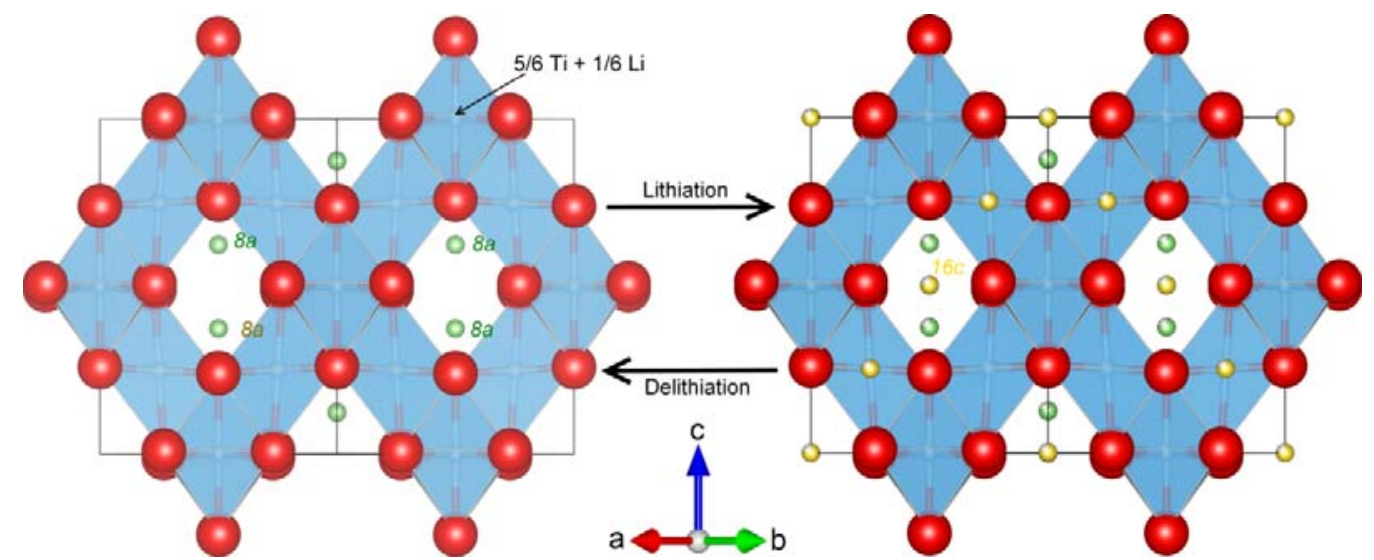

Figure 1. (Left) Crystal structure of the as-prepared $\mathrm{Li}_{4} \mathrm{Ti}_{5} \mathrm{O}_{12}$ as refined using high-resolution neutron powder diffraction data. $\mathrm{Li}(8 a)$ is shown in green, $\mathrm{O}$ in red, and mixed $\mathrm{Ti} / \mathrm{Li}$ sites in light blue. For clarity, Li and $\mathrm{Ti}$ sites are shown as fully occupied. Li at $16 c$ sites (yellow) are also shown in the $\mathrm{Li}_{4+z} \mathrm{Ti}_{5} \mathrm{O}_{12}$ structure (right) following lithiation.

Given that the underlying mechanism of the phase transitions upon lithiation remain controversial and, importantly, may control the performance of the $\mathrm{Li}_{4} \mathrm{Ti}_{5} \mathrm{O}_{12}$ anodes, we have studied the $\mathrm{Li}_{4+2} \mathrm{Ti}_{5} \mathrm{O}_{12}$ structure in detail during battery cycling. Neutron powder diffraction (NPD) data were collected during the non-equilibrium charge and discharge of a $\mathrm{LiFePO}_{4} \|$ $\mathrm{Li}_{4} \mathrm{Ti}_{5} \mathrm{O}_{12}$ battery within the $1.0-3.0 \mathrm{~V}$ window (vs. $\mathrm{Li}_{4} \mathrm{Ti}_{5} \mathrm{O}_{12}$ ). Whilst the details of the $\mathrm{Li}$ diffusion within the $\mathrm{Li}_{4+} \mathrm{Ti}_{5} \mathrm{O}_{12}$ structure is thought to control the lattice response and is discussed in detail elsewhere (Pang et al., 2014a) in work focusing on particle-size differences, here we focus on the structural details and distortion of the $\mathrm{TiO}_{6}$ octahedron. In this work we extract and discuss the Ti-O bond length and $\mathrm{O}-\mathrm{Ti}-\mathrm{O}$ angle which dictate the size of the $\mathrm{TiO}_{6}$ unit and assist in maintaining the stability of the anode during lithiation and delithiation.

\section{EXPERIMENTAL}

\section{A. Preparation}

a) To whom correspondence should be addressed. Electronic mail: vanessa.peterson@ansto.gov.au 
$\mathrm{LiFePO}_{4}$ cathode powder was provided by Tatung Fine Chemicals Co., Taiwan. $\mathrm{Li}_{4} \mathrm{Ti}_{5} \mathrm{O}_{12}$ anode powder was prepared via a sol-gel method using Li acetate $(98 \%$, Acros) and titanium butoxide $(98.0 \%$, Acros). The stoichiometrically mixed powders were dissolved in an adequate amount of ethanol $(99.5 \%$, Shimakyu) and the solution aged for 3 hours to form a white-colored gel. The resulting gel was heated at $80{ }^{\circ} \mathrm{C}$ to yield an organic precursor with a fine white powder product obtained by heat-treating in air at $800{ }^{\circ} \mathrm{C}$ for 4 hours.

A purpose designed $\mathrm{LiFePO}_{4} \| \mathrm{Li}_{4} \mathrm{Ti}_{5} \mathrm{O}_{12}$ pouch-type battery (as shown in Figure 2) was used in the collection of in-situ NPD data. The $\mathrm{LiFePO}_{4}$ cathode was prepared by casting a slurry of the active materials ( $80 \mathrm{wt} . \%)$, acetylene black (10 wt.\%), and polyvinylidene difluoride (PVDF) binder (10 wt.\%) onto $\mathrm{Al}$ foil. The $\mathrm{Li}_{4} \mathrm{Ti}_{5} \mathrm{O}_{12}$ anode was prepared using the same procedure, but with $\mathrm{Li}_{4} \mathrm{Ti}_{5} \mathrm{O}_{12}$ powder as active material. The loading ratio between the anode and cathode was designed to be $\sim 4: 6$ by weight. The electrodes were cut into $1 \times 4 \mathrm{~cm}$ strips. Immobilon-P PVDF membrane (Millipore) was used as a separator due to its lower hydrogen content relative to the conventionally-used Celgard membrane, where the strong incoherent neutron scattering of hydrogen is detrimental to the NPD signal. The $\mathrm{LiFePO}_{4} \| \mathrm{Li}_{4} \mathrm{Ti}_{5} \mathrm{O}_{12}$ battery was prepared by stacking 30 anode/separator/cathode assemblies with a parallel connection. The stack was placed in an Ar-filled glove box for 24 hours and then wrapped in a polypropylene-coated Al foil to form a pouch. Prior to the in-situ NPD experiment, deuterated electrolyte solution (1 M lithium hexafluorophosphate $(99.99 \%$, Sigma-Aldrich) in a 1:1 volume ratio of deuterated dimethyl carbonate $(99.5 \%$, Novachem) to deuterated ethylene carbonate $(98 \%$, Novachem) was injected into the pouch which was heat-sealed under Ar. After 1-day of wetting, the battery was used in the in-situ NPD experiment. During the in-situ NPD experiment the pouch-type battery was cycled galvanostatically using a potentiostat/galvanostat (Autolab PG302N) at currents of $11 \mathrm{~mA}$ (theoretically equivalent to $0.1 \mathrm{C}$ ) for 1 cycle between 1.0 and $3.0 \mathrm{~V}$ (vs. $\mathrm{Li}_{4} \mathrm{Ti}_{5} \mathrm{O}_{12}$ ).

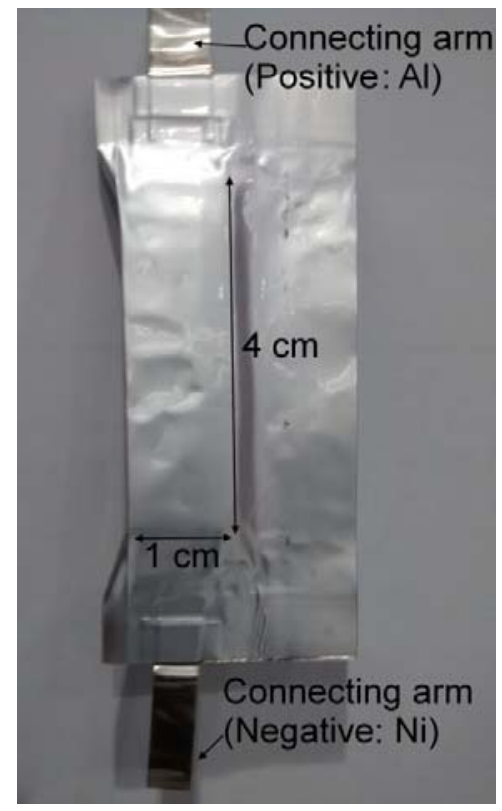

Figure 2. Pouch cell used in the in-situ NPD experiment.

a) To whom correspondence should be addressed. Electronic mail: vanessa.peterson@ansto.gov.au 


\section{B. Data Collection and Analysis}

High-resolution NPD data of the as-prepared $\mathrm{Li}_{4} \mathrm{Ti}_{5} \mathrm{O}_{12}$ sample was collected using ECHIDNA, the high-resolution neutron powder diffractometer at the Open Pool Australian Light-water (OPAL) research reactor at the Australian Nuclear Science and Technology Organisation (ANSTO) (Liss et al., 2006). The neutron beam wavelength was 1.6214(4) $\AA$, determined using the $\mathrm{La}^{11} \mathrm{~B}_{6}$ NIST standard reference material $660 \mathrm{~b}$. The NPD data were obtained in the $2 \theta$ angular range 4 to $164^{\circ}$ with a step size of $0.125^{\circ}$. Rietica ver. 1.77 (Hunter, 1998) was employed to perform Rietveld analysis of the high-resolution NPD data. The refineable parameters included the background coefficients, zero-shift, peak shape parameters, lattice parameters, $\mathrm{O}$ positional parameter, and isotropic atomic displacement parameters. Micrographs of the asprepared $\mathrm{Li}_{4} \mathrm{Ti}_{5} \mathrm{O}_{12}$ were collected using field-emission scanning electron microscopy (SEM) with a SU8000 (Hitachi, Japan). All observations were carried out without a conductive coating under a $10 \mathrm{kV}$ acceleration voltage.

In-situ NPD data of the $\mathrm{LiFePO}_{4}|| \mathrm{Li}_{4} \mathrm{Ti}_{5} \mathrm{O}_{12}$ battery were collected using WOMBAT (Studer et al., 2006), the high-intensity neutron powder diffractometer at the OPAL research reactor at ANSTO. WOMBAT features an area detector that continuously covers $120^{\circ}$ in $2 \theta$ and has a relatively intense neutron beam, allowing the rapid collection of data. A neutron beam with a wavelength of 2.9592(2) $\AA$ was used, determined using the $\mathrm{La}^{11} \mathrm{~B}_{6}$ NIST Standard Reference Material 660b. The diffractograms were obtained with an exposure time of 5 minutes in the angular range $16.1-136.9^{\circ}$ in $2 \theta$ during charge-discharge cycling of the batteries. Sequential Rietveld refinements were carried out using the NPD data using Fullprof with visualization in WinplotR (Rodríguez-Carvajal, 1993; T. Roisnel et al., 2000). The refinements were performed using data in the range $60-120^{\circ}$ in $2 \theta$.

\section{RESULTS AND DISCUSSION}

\section{A. Crystallography and Micro-structure of the $\mathrm{Li}_{4} \mathbf{T i}_{5} \mathbf{O}_{12}$ Anode}

Using high resolution NPD data, the crystallographic details of the anode was established. As reported in Pang et al. (2014a), the anode adopts $F d \overline{3} m$ space group symmetry, with a minor amount, 1.9(3) wt.\%, of monoclinic $\mathrm{Li}_{2} \mathrm{TiO}_{3}$. The crystallographic details are summarized in Pang et al. (2014a). The as-prepared anode particles are cube-like with an average particle-size of $\sim 200 \mathrm{~nm}$.

\section{B. In-Situ Neutron Powder Diffraction}

In-situ NPD data of the battery are shown in Figure 3. In the absence of peak splitting in the NPD pattern for the cathode, we model the anode lattice evolution as single-phase $\mathrm{Li}_{4+\mathrm{z}} \mathrm{Ti}_{5} \mathrm{O}_{12}$ (solid-solution reaction) after Wagemaker et al. (2006), the details of which are presented in Pang et al. (2014a). The two-phase reaction between $\mathrm{LiFePO}_{4}$ and $\mathrm{FePO}_{4}$ in cathode is also observed in Figure 3.

To effectively refine the $\mathrm{O}$ positional parameter, it was necessary to fix the Li occupancy at $8 a$ and $16 c$ sites in the sequential Rietveld refinement, as per previous work (Pang et al., 2014a; Pang et al., 2014b). Figure 4 summarizes the lattice and crystallographic changes occurring during battery cycling, including the variation of lattice parameter, O positional parameter, O-Ti$\mathrm{O}$ bond angle $(\alpha)$, Ti-O bond length, and the estimated Ti oxidation state.

a) To whom correspondence should be addressed. Electronic mail: vanessa.peterson@ansto.gov.au 


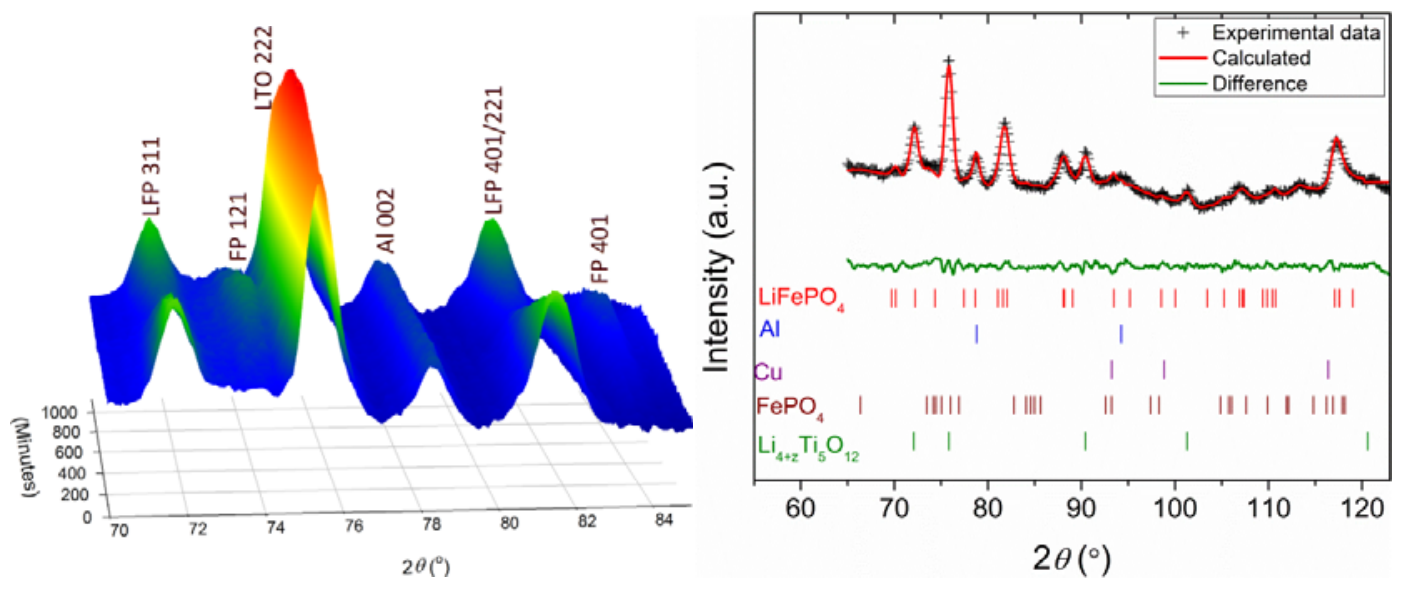

Figure 3. Waterfall plot (left) of a collection of NPD patterns shown for a restricted $2 \theta$ range taken during battery charge and discharge. Labels are phase reflections for $\mathrm{LiFePO}_{4}$ (LFP), $\mathrm{FePO}_{4}(\mathrm{FP}), \mathrm{Li}_{4+\mathrm{z}} \mathrm{Ti}_{5} \mathrm{O}_{12}$ (LTO), and Al. A typical Rietveld refinement profile before cycling (right) is also shown. The figures-of-merit for the refinements were in the range $\chi^{2}=3.9-8.9, \mathrm{R}_{\mathrm{wp}}$ $=14.3-17.1$, and Bragg- $\mathrm{R}=1.0-3.9$.

During charge, the anode lithiates and the lattice undergoes rapid expansion, followed by a gradual contraction. The non-linearity in the lattice response is attributed to the interplay of the amount and site of Li insertion (Sharma et al., 2013; Pang et al., 2014a), with population of Li at the two crystallographic sites (i.e., $8 a$ and 16c) having a different effect on the lattice. Interestingly, these lattice changes are not reflected in the trend of $\mathrm{TiO}_{6}$ octahedral distortion, with no measureable distortion occurring during the initial lattice expansion. We find that the gradual lattice contraction, associated with population of $\mathrm{Li}$ at the $16 \mathrm{c}$ site in the anode (Pang et al., 2014a), is strongly correlated to the trend of the $\mathrm{TiO}_{6}$ distortion. The repositioning of the $\mathrm{O}$ atom in response to lithiation at the $16 c$ site is important in maintaining the stability of the anode, and reflects the trend in the estimated oxidation state of the Ti. As shown in Figure 4, during battery charge the $\mathrm{O}$ atom moves further from the Ti atom, at $(0.5,0.5,0.5)$, resulting in an increase in the length of Ti-O bond that occurs alongside a decrease in the average Ti valence as estimated by the bond-valence summation (BVS) method (Brown et al., 1985). We note that the BVS method will yield an approximate Ti valence as the Ti shares the $16 d$ site with Li. The ideal $\mathrm{Ti}^{4+}-\mathrm{O}^{2-}$ bond-length of $1.815 \AA$ and empirical constant of $0.37 \AA$ (Brown et al., 1985) are used in this estimation. The bond angle or $\alpha$ also varies with the oxygen positional parameter, resulting in distortion of the $\mathrm{TiO}_{6}$ octahedron (Figure 5). The combination of bond angle and length changes allow the $\mathrm{TiO}_{6}$ octahedron to deform and distort, stabilizing the structure during lithiation and delithiation processes. Alongside the $\mathrm{Li}$ repositioning, it is the $\mathrm{O}$ positional parameter changes during battery charge and discharge that completes the picture of the $\mathrm{Li}_{4} \mathrm{Ti}_{5} \mathrm{O}_{12}$ structural response and anode function.

a) To whom correspondence should be addressed. Electronic mail: vanessa.peterson@ansto.gov.au 


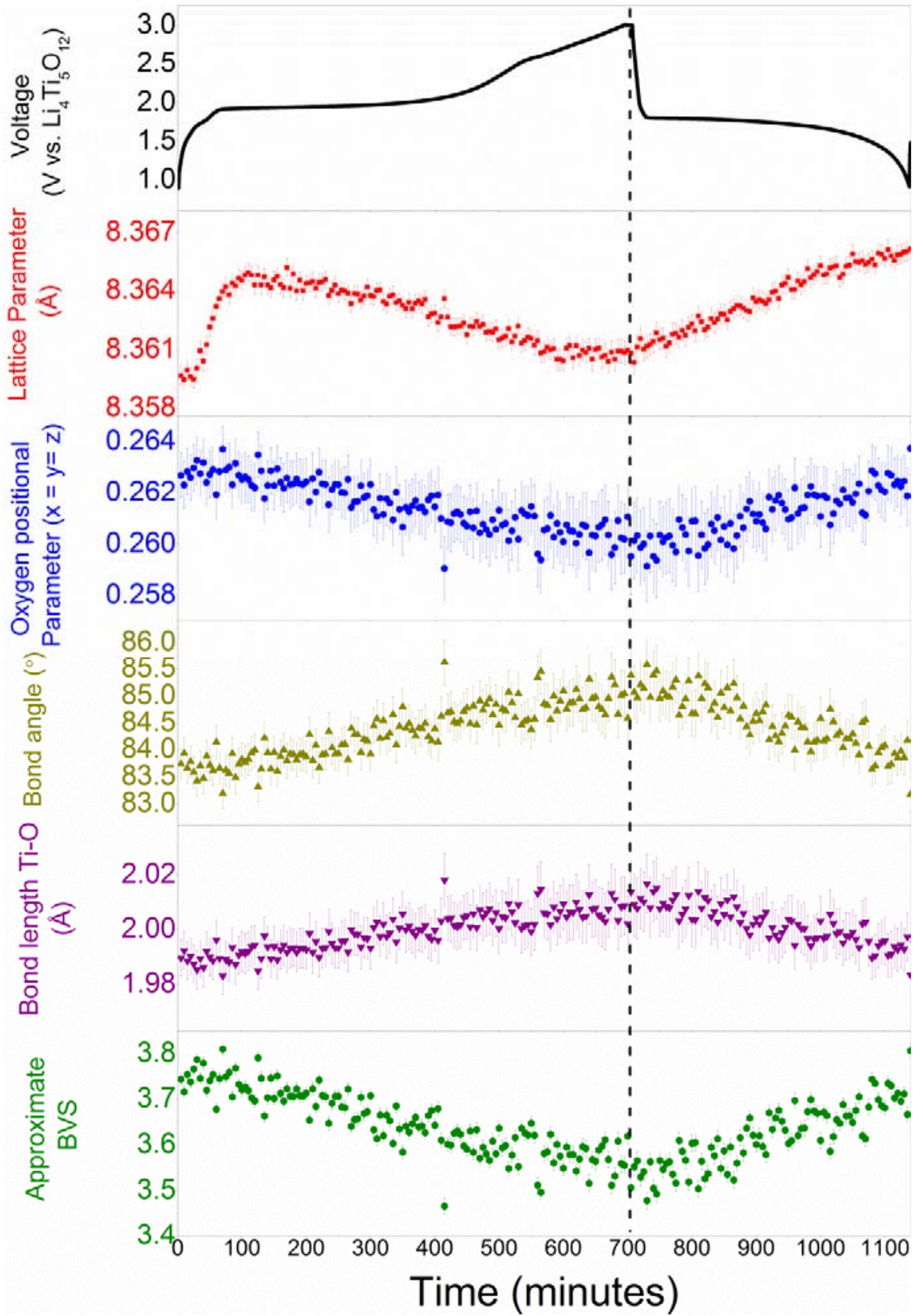

Figure 4. Refined anode lattice (red) and $\mathrm{O}$ positional parameter (blue), as well as the $\alpha$ bond angle (olive) and Ti-O bond length (violet) during battery charge and discharge. The Ti oxidation state (green) is estimated using the approximate BVS method. The charge-discharge profile of the battery is also shown (black)

a) To whom correspondence should be addressed. Electronic mail: vanessa.peterson@ansto.gov.au 


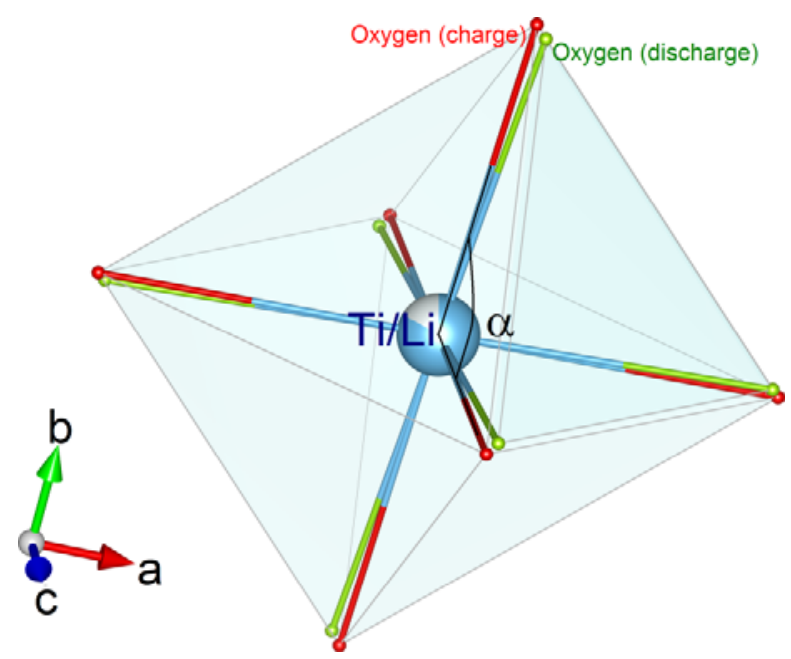

Figure 5. Overlaid structures of the $\mathrm{TiO}_{6}$ unit in the anode at the charged $(\mathrm{O}$ atom in red) and discharged (O atom in green) battery states showing that the O-Ti-O bond angle $(\alpha)$ is larger at the charged state and narrower at the discharged state. All $\mathrm{O}$ atoms are crystallographically equivalent.

\section{CONCLUSION}

We have successfully monitored the crystallographic change in the $\mathrm{Li}_{4+z} \mathrm{Ti}_{5} \mathrm{O}_{12}$ anode within in a battery during charge and discharge. We report the details of the change to the $\mathrm{TiO}_{6}$ structural unit occurring during Li diffusion that contributes to the structural stability of this "zero strain" anode. We find that whilst the initial expansion of the lattice upon lithiation is not reflected in the trend of $\mathrm{TiO}_{6}$ octahedral distortion, the gradual lattice contraction experienced during further lithiation is strongly correlated to the trend of the $\mathrm{TiO}_{6}$ distortion, and associated with the repopulation of $\mathrm{Li}$ at the $16 c$ site in the anode.

\section{ACKNOWLEDGEMENTS}

The authors acknowledge the travel support funded by National Synchrotron Radiation Research Center (2013-3-100-1). The research was supported by the Australian Nuclear Science and Technology's (ANSTO) Energy Materials project. The authors are also grateful to Professor Lin, Jeng-Yu of Tatung University for providing $\mathrm{Li}_{4} \mathrm{Ti}_{5} \mathrm{O}_{12}$ sample, Tatung Fine Chemicals Co., Taiwan for providing $\mathrm{LiFePO}_{4}$ sample and the staff members at the Bragg Institute, ANSTO for their operations support.

a) To whom correspondence should be addressed. Electronic mail: vanessa.peterson@ansto.gov.au 
Brown, I. D., and Altermatt, D. (1985). "Bond-valence parameters obtained from a systematic analysis of the Inorganic Crystal Structure Database," Acta Crystallogr. Sect. B, 41, 244-247.

Cho, J., Kim, Y. J., Kim, T.-J., and Park, B. (2001). "Zero-Strain Intercalation Cathode for Rechargeable Li-Ion Cell," Angew. Chem. Int. Ed., 113, 3471-3473.

Hunter, B. "Rietica - A Visual Rietveld Program". International Union of Crystallography Commission on Powder Diffraction Newsletter No. 20, (Summer) http://www.rietica.org.

Liss, K.-D., Hunter, B., Hagen, M., Noakes, T., and Kennedy, S. (2006). "Echidna- the new highresolution powder diffractometer being built at OPAL," Physica B, 385-386, Part 2, 1010-1012.

Ohzuku, T., Ueda, A., and Yamamoto, N. (1995). "Zero-Strain Insertion Material of $\mathrm{Li}\left[\mathrm{Li}_{1 / 3} \mathrm{Ti}_{5 / 3}\right] \mathrm{O}_{4}$ for Rechargeable Lithium Cells," J. Electrochem. Soc., 142, 1431-1435.

Pang, W. K., Peterson, V. K., Sharma, N., Shiu, J.-J., and Wu, S.-h. (2014a). "Lithium Migration in $\mathrm{Li}_{4} \mathrm{Ti}_{5} \mathrm{O}_{12}$ Studied Using in Situ Neutron Powder Diffraction," Chem. Mater., 26, 2318-2326.

Pang, W. K., Sharma, N., Peterson, V. K., Shiu, J.-J., and Wu, S.-H. (2014b). "In-situ neutron diffraction study of the simultaneous structural evolution of a $\mathrm{LiNi}_{0.5} \mathrm{Mn}_{1.5} \mathrm{O}_{4}$ cathode and $\mathrm{Li}_{4} \mathrm{Ti}_{5} \mathrm{O}_{12}$ anode in a $\mathrm{LiNi}_{0.5} \mathrm{Mn}_{1.5} \mathrm{O}_{4}|| \mathrm{Li}_{4} \mathrm{Ti}_{5} \mathrm{O}_{12}$ full cell," J. Power Sources, 246, 464-472.

Rodríguez-Carvajal, J. (1993). "Recent Advances in Magnetic Structure Determination by Neutron Powder Diffraction," Physica B, 192, 55-69.

Ronci, F., Reale, P., Scrosati, B., Panero, S., Rossi Albertini, V., Perfetti, P., di Michiel, M., and Merino, J. M. (2002). "High-Resolution In-Situ Structural Measurements of the $\mathrm{Li}_{4 / 3} \mathrm{Ti}_{5 / 3} \mathrm{O}_{4}$ "Zero-Strain" Insertion Material," J. Phys. Chem. B, 106, 3082-3086.

Sharma, N., Yu, D., Zhu, Y., Wu, Y., and Peterson, V. K. (2013). "Non-equilibrium Structural Evolution of the Lithium-Rich $\mathrm{Li}_{1+\mathrm{y}} \mathrm{Mn}_{2} \mathrm{O}_{4}$ Cathode within a Battery," Chem. Mater., 25, 754-760.

Studer, A. J., Hagen, M. E., and Noakes, T. J. (2006). "Wombat: The high-intensity powder diffractometer at the OPAL reactor," Physica B, 385-386, Part 2, 1013-1015.

T. Roisnel, and Rodriguez-Carvajal, J. 2000. WinPLOTR: A Windows Tool for Powder Diffraction Patterns Analysis. Paper read at Materials Science Forum, Proceedings of the Seventh European Powder Diffraction Conference (EPDIC 7).

Tarascon, J. M., and Armand, M. (2001). "Issues and Challenges Facing Rechargeable Lithium Batteries," Nature, 414, 359-367.

Wagemaker, M., Simon, D. R., Kelder, E. M., Schoonman, J., Ringpfeil, C., Haake, U., LützenkirchenHecht, D., Frahm, R., and Mulder, F. M. (2006). "A Kinetic Two-Phase and Equilibrium Solid Solution in Spinel $\mathrm{Li}_{4+\mathrm{x}} \mathrm{Ti}_{5} \mathrm{O}_{12}, "$ Adv. Mater., 18, 3169-3173.

a) To whom correspondence should be addressed. Electronic mail: vanessa.peterson@ansto.gov.au 